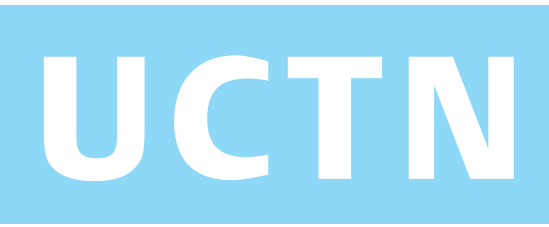

\title{
A Percutaneous Endoscopic Gastrostomy Tube Pushed Through the Posterior Wall of the Stomach as far as the Pancreas During Nonendoscopic Tube Exchange
}

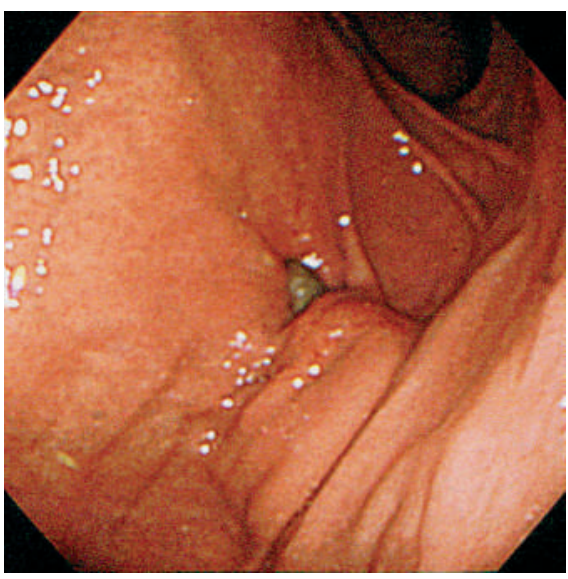

Figure 1 Endoscopic examination revealed that the Foley catheter had gone through the posterior wall of the stomach.

The safety and efficacy of percutaneous endoscopic gastrostomy (PEG) have been well documented [1,2]. With regard to the removal of PEG tubes, the standard method used recently has been nonendoscopic removal: the percutaneous removal method should cost less and be less time-consuming because it obviates the need for an endoscopy. However, complications arising from such PEG tube exchange procedures have been reported $[3,4]$. We encountered a patient who developed problems as a result of a PEG tube exchange, in whom it was discovered that the the PEG tube had gone through the posterior wall of the stomach, reaching as far as the anterior aspect of the pancreas.

A 78-year-old woman underwent the insertion of a 16-Fr Foley catheter using a stylet under pressure instead of a new PEG tube because the insertion of a new tube was difficult. Sudden-onset abdominal pain and a fever of over 37.9 C occurred as soon as enteral feeding was commenced and she was transferred to our hospital. Endoscopic examination revealed that the Foley catheter had gone through the posterior wall of the stomach (Figure 1). Computed tomography revealed that the tip of the catheter had reached the anterior aspect of the pan-

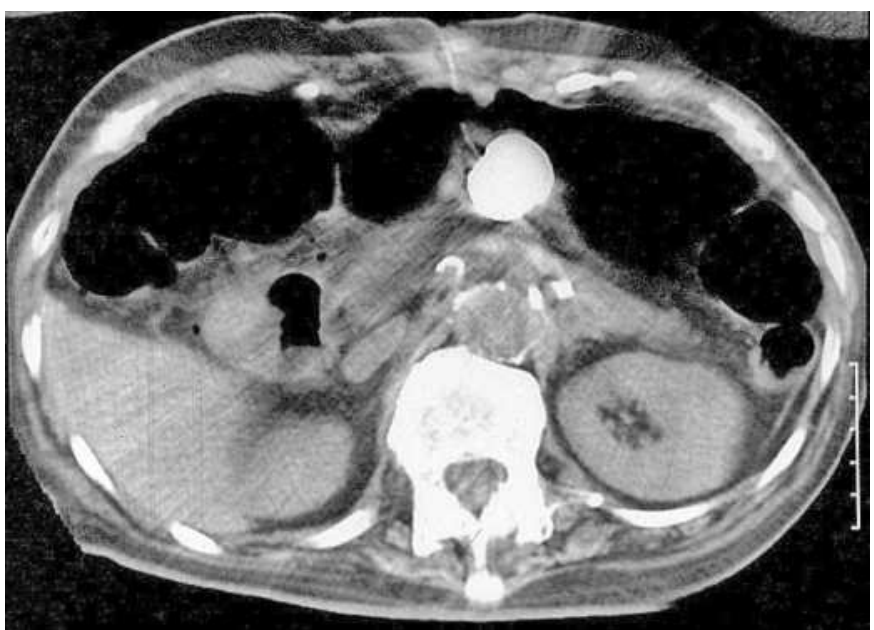

Figure 2 Computed tomography revealed that the Foley catheter's balloon had gone through the posterior wall of the stomach and reached the front of the pancreas.

creas (Figure 2). After deflating the balloon by $5 \mathrm{ml}$ per week, a second endoscopic examination revealed converging folds in the posterior wall of the stomach. A new PEG tube was inserted endoscopically using the pull technique.

Mechanical stimulation of the mucosa of the stomach by the tip of the PEG tube has been reported to lead to the development of gastric ulcer [5]. However, the gastric ulcer in our case was caused by the excessive force used to insert the new PEG tube and this was unacceptable. Endoscopists skilled in PEG techniques should carry out PEG tube exchanges in order to avoid malpositioning of PEG tubes.

\section{S. Kasamaki ${ }^{1,2}$, T. Kamano²,}

Y. Hayashida ${ }^{3}$, H. Motoyama ${ }^{1}$, H. Yokota ${ }^{1}$

${ }^{1}$ Department of Surgery, Hokota Hospital, Ibaraki Prefecture, Japan

2 Department of Coloproctological Surgery, Juntendo University, School of Medicine, Tokyo, Japan

${ }^{3}$ Department of General Medicine, Juntendo University, School of Medicine, Tokyo, Japan.

\section{References}

${ }^{1}$ Ponsky JL. Percutaneous endoscopic gastrostomy: techniques of removal and replacement. Gastrointest Endosc Clin N Am 1992; 2: 215-221

${ }^{2}$ Stephen AM, Wei-Kuo C. Complications of enteral access. Gastrointest Endosc 2003; 58: $739-751$

${ }^{3}$ Cass OW, Rowland K, Bartram B et al. Insertion, efficacy, and removal of a nonendoscopically removable percutaneous endoscopic gastrostomy (PEG) tube. Surg Endosc 1999; 13: 516-519

${ }^{4} \mathrm{Vu}$ CK. Buried bumper syndrome: old problem, new tricks. J Gastroenterol Hepatol 2002; 17: 1125-1128

${ }^{5}$ Kanie J, Akatsu H, Suzuki Y et al. Mechanism of the development of gastric ulcer after percutaneous endoscopic gastrostomy. Endoscopy 2002; 34: 480482

\section{Corresponding Author}

\section{S. Kasamaki, M.D.}

Department of Coloproctological Surgery, Juntendo University, School of Medicine

Hongo 2-1-1

Bunkyo-Ku

Tokyo 113-8421

Japan

Fax: $\quad+81-3-3812-1056$

E-mail: kasamaki@hh.iij4u.or.jp 